\title{
Photocatalytic Degradation of Organic Dye Methyl Orange with Phosphotungstic Acid
}

\author{
Weiping Wang, Shuijin Yang* \\ College of Chemistry and Environmental Engineering, Hubei Key Laboratory of Pollutant Analysis \& \\ Reuse Technology, Hubei Normal University, Huangshi, China \\ E-mail: yangshuijin@163.com \\ Received September 29, 2010; revised November 2, 2010; accepted November 4, 2010
}

\begin{abstract}
Silicotungstic acid and phosphotungstic acid were prepared and characterized by Fourier Transform Infrared Spectroscopy (FTIR)and X-ray diffraction (XRD). The results showed that the prepared catalysts possess classical Keggin structure. The factors on the degradation of methyl orange, such as the kind of catalyst, the amount of catalyst, the original concentration of dye and illumination time were investigated under metal halide lamp. The degradation of methyl orange is up to $93.6 \%$ with phosphotungstic acid at the best reaction conditions at $8.89 \mathrm{~g} / \mathrm{L}$ concentration of phosphotungstic acid, $5.56 \mathrm{mg} / \mathrm{L}$ concentration of methyl orange and 80 min illumination time.
\end{abstract}

Keywords: Phosphotungstic Acid, Photocatalytic, Degradation, Methyl Orange

\section{Introduction}

The wastewater of textile dye draining into the river without treatment would bring out serious pollution of Water resource and threatening of ecology environment and human health. At present, the industrial methods for dye waste treatment include adsorption, precipitation, electrical remediation, oxidation, and biological degradation. But all these ways cost much money, and/or create secondary contamination [1]. Since the discovery of photoelectrochemical splitting of water on n-type $\mathrm{TiO}_{2}$ electrodes [2], photochemistry has possessed many practical applications, such as in optoelectronic devices or in the field of industrial and environmental catalysis [3-4]. Anatase $\mathrm{TiO}_{2}$ has attracted much attention due to their efficient decomposition ability for organic pollutants under irradiation with UV light with wavelength shorter than $387 \mathrm{~nm}$ [5-7]. In the same way, many POM systems share the same general photochemical characteristics as the semiconductor photocatalysts due to their combination of physical and chemical properties, in terms of molecular and electronic versatility, reactivity, and stability [5]. Zhu xiuhua [8-9] has studied the photocatalytic degradation of dye wastewater with phosphotungstic acid and silicotungstic acid. The photocatalytic reductive of

"Financially supported by the Natural Science Foundation of Hubei Province, China (2005ABA053).
$\mathrm{Cr}(\mathrm{VI})$ and organics using polyoxometalates was researched by E. Gkika [10]. Yoon [11] has reported the degradation of methyl orange (MO) in the $\mathrm{TiO}_{2}$ colloid adding to phosphotungstic acid aqueous solution, they found the catalytic activity increased remarkably due to the recombination optical excitation of $\mathrm{POMs}$ and $\mathrm{TiO}_{2}$. The most used optical source was high energy ultraviolet which consumed huge amounts of energy sources and needed strict instruments in the previous literature. In this paper, we prepared two catalysts, i.e. silicotungstic acid and phosphotungstic acid, organic dye $\mathrm{MO}$ was decomposed under a common metal halide lamp exciting the whole range of wavelength simulating the sun, and their catalysis activity was compared, the factors on the degradation of MO were investigated in detail.

\section{Materials and Methods}

\subsection{Materials}

All the chemicals in the present work are of analytical grade and used as such without further purification. MO was obtained from Shanghai Reagent 3th Factory, $\mathrm{Na}_{2} \mathrm{SiO}_{3} \cdot 9 \mathrm{H}_{2} \mathrm{O}$ was from Tianjing Tianda Chemical Reagent Factory, $\mathrm{Na}_{2} \mathrm{WO}_{4} \cdot 2 \mathrm{H}_{2} \mathrm{O}$ was from Beijing Chemical Factory, $\mathrm{Na}_{2} \mathrm{HP}_{4} \cdot 12 \mathrm{H}_{2} \mathrm{O}$ was from Chengdu Chemical Reagent Factory, $\mathrm{H}_{2} \mathrm{SO}_{4}$ was from Kaifeng Dongda 
Chemical Co. Ltd., $\mathrm{HCl}$ was from Xinyang Chemical Reagent Factory, ether was from Tianjin Shentai Chemical Reagent Co. Ltd.; metal halide lamp was obtained from Lianyungang Mantianxing Lighting Electrical Appliance Co. Ltd (power $400 \mathrm{~W}$ ). All the solutions were prepared with deionized water.

\subsection{Preparation of $\mathrm{H}_{4} \mathrm{SiW}_{12} \mathrm{O}_{40} \times \mathrm{H}_{2} \mathrm{O}$ and $\mathrm{H}_{3} \mathrm{PW}_{12} \mathrm{O}_{40} \times \mathrm{H}_{2} \mathrm{O}$ Photocatalyst}

$\mathrm{H}_{4} \mathrm{SiW}_{12} \mathrm{O}_{40} \cdot x \mathrm{H}_{2} \mathrm{O}(\mathrm{SiW})$ was prepared according to the following steps. Frist, $50 \mathrm{~g} \mathrm{Na}_{2} \mathrm{WO}_{4} \cdot 2 \mathrm{H}_{2} \mathrm{O}$ and $100 \mathrm{~mL}$ deionized water were added into $250 \mathrm{~mL}$ three-necked flask, dissolving under vigorously stiring and heating; then $4 \mathrm{~g} \mathrm{Na}_{2} \mathrm{SiO}_{3} \cdot 9 \mathrm{H}_{2} \mathrm{O}$ was slowly added into the threenecked flask; then, $25 \mathrm{ml} \mathrm{HCl}$ was added dropwise with constant voltage dropping funnel in water bath at $95^{\circ} \mathrm{C}$ approximately, retaining at least 35 minutes, and continuing to heat 30 minutes; Silicic acid precipitate was got with water pump, transfering the cooling filtrate into separating funnel and adding into ether as the same volume of the filtrate; add dropwise 1:1.5 $(\mathrm{V} / \mathrm{V}) \mathrm{H}_{2} \mathrm{SO}_{4}$ $5 \sim 10 \mathrm{ml}$ until no extraction liquid dropped. Vibrating sufficiently, the lower levels grease was separated after standing. Extract repeatedly with ether and separate the grease on the evaporation pan (adding into $1 \sim 2 \mathrm{~mL}$ water). Standing 12 hours in the fuming cupboard under room temperature, the white crystal was dried for 2 hours at 70 ${ }^{\circ} \mathrm{C}$; the product was $\mathrm{H}_{4} \mathrm{SiW}_{12} \mathrm{O}_{40} \cdot x \mathrm{H}_{2} \mathrm{O}$.

$\mathrm{H}_{3} \mathrm{PW}_{12} \mathrm{O}_{40} \cdot x \mathrm{H}_{2} \mathrm{O}(\mathrm{PW})$ was prepared according to the following steps. Frist, $50 \mathrm{~g} \mathrm{Na}_{2} \mathrm{WO}_{4} \cdot 2 \mathrm{H}_{2} \mathrm{O}$ and $100 \mathrm{~mL}$ deionized water were added into $250 \mathrm{~mL}$ three-necked flask, dissolving under vigorously stiring and heating; then $11 \mathrm{~g} \mathrm{Na}_{2} \mathrm{HP}_{4} \cdot 12 \mathrm{H}_{2} \mathrm{O}$ was slowly added into the three-necked flask. $32 \mathrm{ml} \mathrm{HCl}$ was added drop with constant voltage dropping funnel in water bath at $95^{\circ} \mathrm{C}$ approximately, reacting for 2.5 hours; transfer the cooling reaction liquid into separating funnel and add into $100 \mathrm{~mL}$ ether with several times. Vibrating sufficiently, the lower levels grease was separated on the evaporation pan(adding into $1-2 \mathrm{~mL}$ water). Standing for 12 hours in the fuming cupboard under room temperature, the pale yellow crystal was dried for 2 hours at $70^{\circ} \mathrm{C}$; the product was $\mathrm{H}_{3} \mathrm{PW}_{12} \mathrm{O}_{40} \cdot x \mathrm{H}_{2} \mathrm{O}$.

\subsection{Instruments of Characterization}

The catalysts were characterized by various techniques like Fourier Transform Infrared Spectroscopy (FTIR) and X-ray diffraction (XRD). The FTIR spectra were recorded on a Nicolet 6700 FTIR spectrometer (USA) using $\mathrm{KBr}$ self-supported pellet technique. The XRD of catalysts were obtained by D8 ADVANCE X-Ray
(Brook, Germany) using $\mathrm{CuK}_{\alpha}$ radiation from $2 \theta=$ $5^{\circ} \sim 70^{\circ}$.

\subsection{Photocatalytic Experiments}

The reaction tank is a airtight opaque cuboid iron box with capacity $650 \mathrm{~mm} \times 350 \mathrm{~mm} \times 525 \mathrm{~mm}$. The light source vertically irradiate the reaction liquid with a distance of $140 \mathrm{~mm}$. Cooling water surrounded the reactor to keep the reaction temperature stable.

A certain concentration of $\mathrm{MO}$ and a certain amount of catalyst were added into reactor. At given intervals of illumination, a sample of reaction solution was taken out and analyzed by U-3010 UV-Vis (Hitachi, Japan) spectrophotometer.

\section{Results and Discussion}

\subsection{Characterization of Catalysts}

The range of characteristic absorption peaks of $\mathrm{SiW}$ are

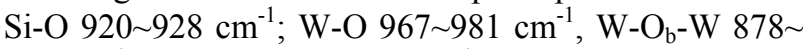
$894 \mathrm{~cm}^{-1}, \mathrm{~W}-\mathrm{O}_{\mathrm{c}}-\mathrm{W} 780 \sim 797 \mathrm{~cm}^{-1}$ respectively. There are four characteristic absorption peaks $926 \mathrm{~cm}^{-1}, 982 \mathrm{~cm}^{-1}$, $883 \mathrm{~cm}^{-1}$ and $789 \mathrm{~cm}^{-1}$ respectively in Figure 1(a).

The range of characteristic absorption peaks of $\mathrm{PW}$ are P-O 1080 1081 cm $\mathrm{cm}^{-1}$, W-O 926 995 $\mathrm{cm}^{-1}, \mathrm{~W}-\mathrm{O}_{\mathrm{b}}-\mathrm{W}$ $890 \sim 900 \mathrm{~cm}^{-1}$, W-O $-\mathrm{C}$-W 805 810 $\mathrm{cm}^{-1}$ respectively. There are four characteristic absorption peaks $1080 \mathrm{~cm}^{-1}$, $985 \mathrm{~cm}^{-1}, 891 \mathrm{~cm}^{-1}$ and $804 \mathrm{~cm}^{-1}$ respectively in Figure 1(b). The results of spectra of FTIR are the same with the reports of literature basically [12].

The $2 \theta$ of XRD strong diffraction absorption peak of SiW are $8^{\circ} \sim 10^{\circ} 、 20^{\circ} \sim 24^{\circ} 、 26^{\circ} \sim 28^{\circ} 、 32^{\circ} \sim 35^{\circ}$, respectively. The diffraction peak are $8.1^{\circ}, 23.2^{\circ}, 25.4^{\circ}$ and $34.7^{\circ}$ in Figure 2(a); The $2 \theta$ of strong XRD diffraction absorption peak of PW are $6^{\circ} \sim 10^{\circ}, 15^{\circ} \sim 22^{\circ}, 24^{\circ} \sim 30^{\circ}, 33^{\circ} \sim 36^{\circ}$. The diffraction peak are $10.3^{\circ}, 20.7^{\circ}, 25.3^{\circ}$ and $34.6^{\circ}$ in Figure 2(b). The result proved that $\mathrm{SiW}$ and PW possessed Keggin structure [13,14].

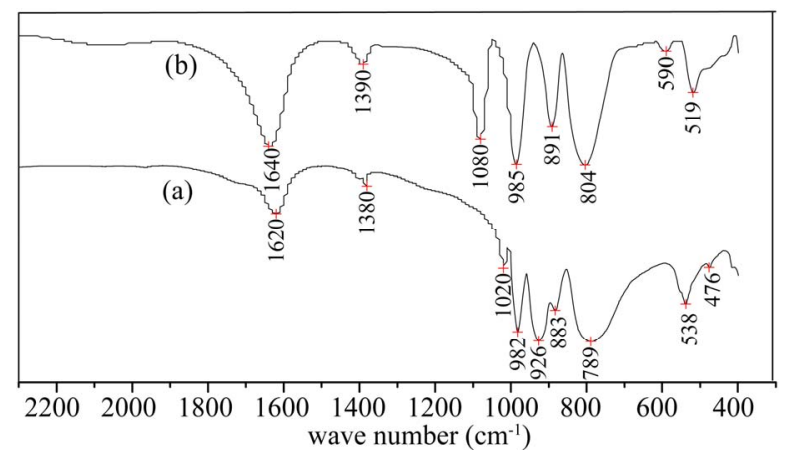

Figure 1. FT-IR spectra of catalysts (a) SiW; (b) PW. 


\subsection{Photocatalytic Activity}

\subsubsection{Control Experiment}

A certain of $\mathrm{MO}$ was added into reactor, stirring by magnetic force and irradiating under metal halide lamp, at given intervals of illumination, some reaction liquid was taken out to be detected on UV-Vis spectrophotometer.

The spectra of the reaction were superimposed (Figure 3(a)), the absorbance of MO didn't change when there was no catalyst. It is suggested that MO didn't decompose without catalyst.

A certain of $\mathrm{MO}$ and $\mathrm{PW}$ were added into reactor, stirring by magnetic force, at given intervals of illumination, some reaction liquid was taken out to be detected on $\mathrm{UV}$-Vis spectrophotometer. The spectra of the reaction were also superimposed (Figure 3(b)), the absorbance of MO didn't change when there was no illumination. It is suggested that MO didn't decompose without illuminetion.

The maximum absorbance wavelength of methyl orange was shifed from $462 \mathrm{~nm}$ to $504 \mathrm{~nm}$ by comparation of $\mathrm{A}$ and $\mathrm{B}$ in Figure 3 because the maximum absorbance wavelength of methyl orange will increase in the presence of acid. The catalyst $\mathrm{H}_{3} \mathrm{PW}_{12} \mathrm{O}_{40}$ is a kind of strong Bronsted acid in this reaction system $[15,16]$.

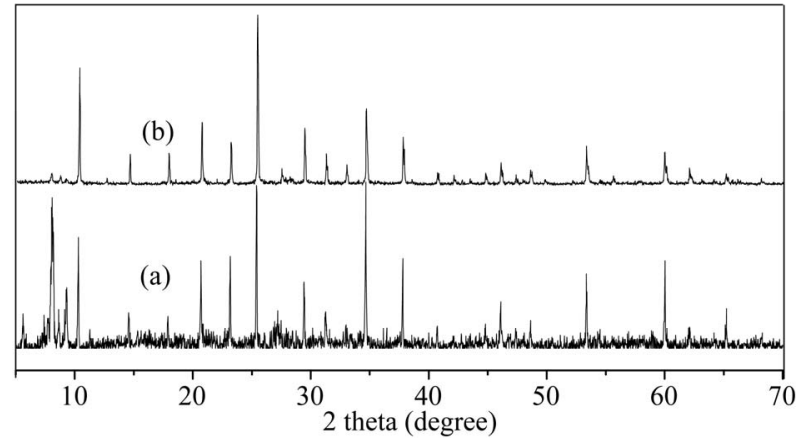

Figure 2. XRD spectra of catalysts (a) SiW; (b) PW.

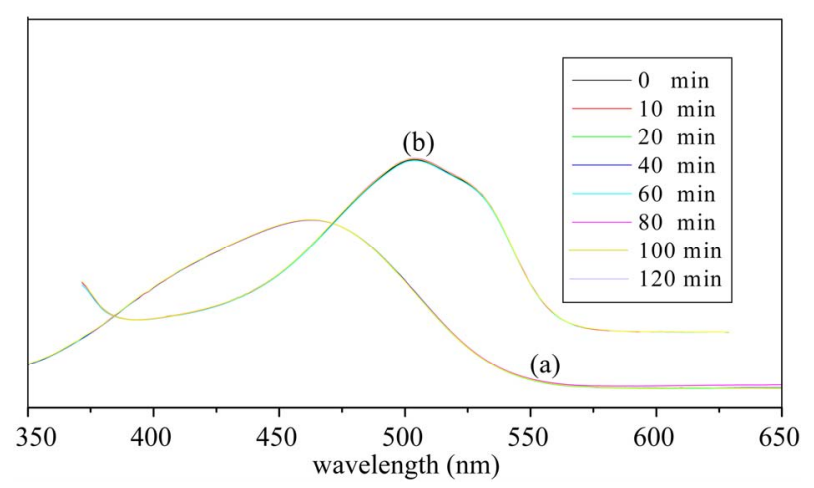

Figure 3. Ultraviolet spectra of no catalysts (a) and no light (b)

\subsubsection{Choice of Catalysts}

Most of the heteropolyacids possessed oxidability, however, they have different oxidability to different compounds. Therefore, it is important to found the appropriate catalyst for the target compound.

A certain of MO was added into two reactors, $50 \mathrm{mg}$ PW and $50 \mathrm{mg}$ SiW were added into respectively, stirring by magnetic force and irradiating under metal halide lamp, at given intervals of illumination, some reaction liquid was taken out to be detected on UV-Vis spectrophotometer. It is observed that (Figure 4) more than $90 \%$ of MO was decomposed with PW after 70 minutes, but only $21 \%$ of MO was decomposed with $\mathrm{SiW}$ after 140 minutes. It is suggested the photocatalytic activity of PW is better than SiW, so PW was chosen for the catalyst to decompose the MO. The result was the same with most literatures $[1,15,17]$.

\subsubsection{Effect of Catalyst Amount}

It is waste to use too much catalyst and it will hinder the degradation of organic compound [18]. Meanwhile, too little catalyst will decrease the degradation. So, the choice of catalyst amount is important. The PW amounts $10 \mathrm{mg}, 20 \mathrm{mg}, 30 \mathrm{mg}, 40 \mathrm{mg}, 50 \mathrm{mg}$ adding into $45 \mathrm{~mL}$ $5.56 \mathrm{mg} / \mathrm{L} \mathrm{MO}$ were investigated for effective MO degradation (Figure 5). It is observed that, increasing

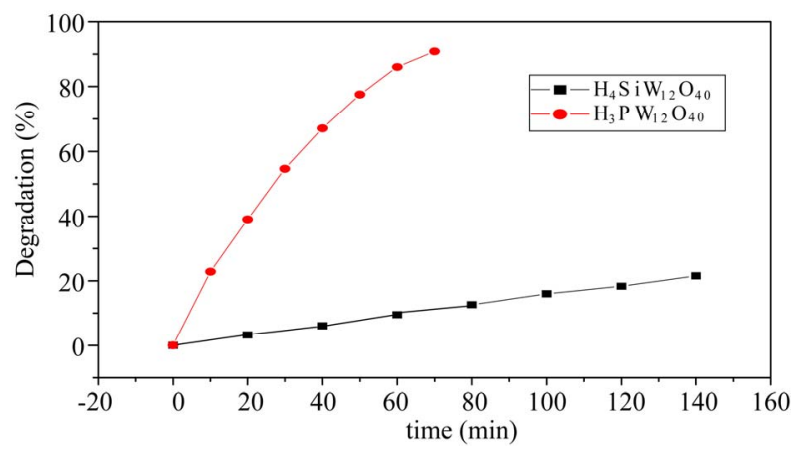

Figure 4. Degradation of MO with SiW and PW.

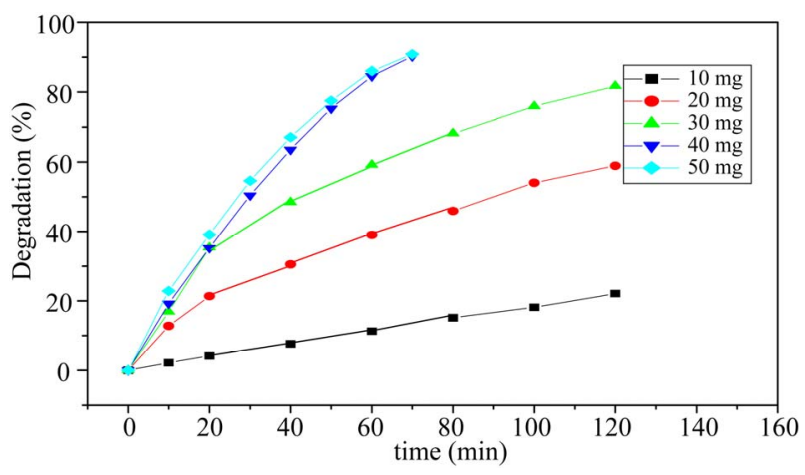

Figure 5. Degradation of MO with different amount of PW. 
amounts $10 \mathrm{mg} \sim 50 \mathrm{mg}$, the degradation has increased but the increasing extent was smaller when the amount was $40 \mathrm{mg}$ to $50 \mathrm{mg}$. Considering to the practical cost, in the present study, $40 \mathrm{mg}$, i.e. $8.89 \mathrm{~g} / \mathrm{L}$, is found to be the optimum catalyst amount for efficient degradation of MO.

\subsubsection{Effect of Original Concentration}

The effect of MO concentration is an important parameter for photocatalytic degradation activity over known catalyst amount. The $4.54 \mathrm{mg} / \mathrm{L}, 5.56 \mathrm{mg} / \mathrm{L}, 6.52 \mathrm{mg} / \mathrm{L}$, $7.53 \mathrm{mg} / \mathrm{L}, 10.00 \mathrm{mg} / \mathrm{L}$ concentrations of MO were studied with $8.89 \mathrm{~g} / \mathrm{L}$ PW catalyst amount. It is seen from Figure 6 the degradation was higher when the concentration was lower. However, the degradation of $4.54 \mathrm{mg} / \mathrm{L}$ almost was the same with $5.56 \mathrm{mg} / \mathrm{L}$ at 70 minutes. According to the practical situation, it is useful to decompose higher concentration wastewater, hence, $5.56 \mathrm{mg} / \mathrm{L}$ MO was chosen for the degradation of MO.

\subsubsection{Effect of Illumination Time}

The effect of illumination time was also an important parameter for photocatalytic degradation activity. The degradation will decrease when concentration decrease and the efficiency is concerned with the illumination time. The illumination time was longer, the efficiency was lower. Figure 7 indicates the increased extend was

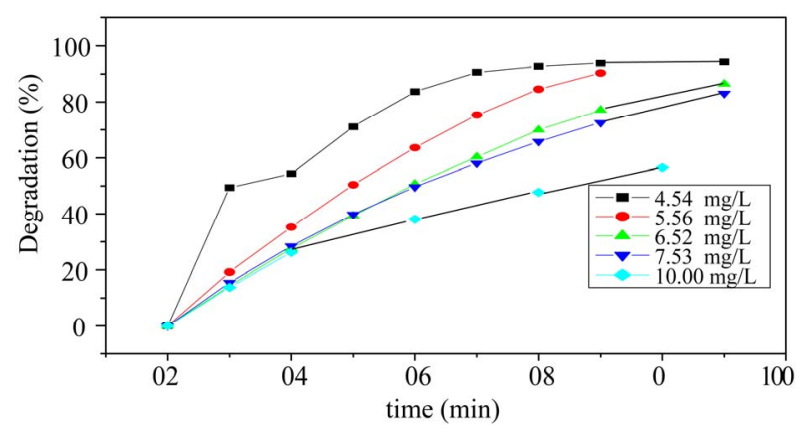

Figure 6. Degradation of MO with different original concentration.

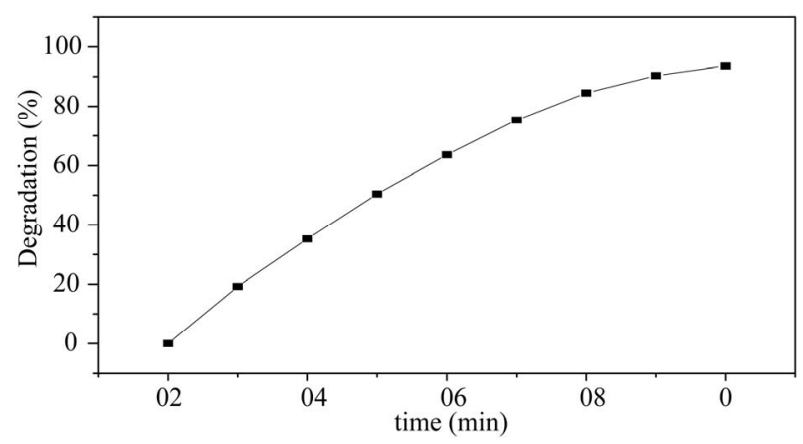

Figure 7. Degradation of methyl orange with different illumination time. decreasing and the MO was almost decomposed entirely after 80 minutes. Hence, the optimum illumination time for degradation of MO is 80 minutes. Many compounds were decomposed entirely more than two hours [19], however, MO was decomposed almost entirely in 80 minutes in this system, it is suggested the catalyst was an efficient catalyst for the degradation of MO.

\section{Conclusions}

Two kinds of catalysts were prepared, i.e. Silicotungstic acid and phosphotungstic acid, it is suggested that the catalysts possessed classical Keggin structure according to the characterization of FTIR and XRD.

It is found that the photocatalytic degradation activity of PW exceeded SiW according to the degradation of MO under metal halide lamp with the prepared catalysts.

MO was decomposed almost entirely under metal halide lamp with PW, the result revealed that the degradation was up to $93.6 \%$ at $8.89 \mathrm{~g} / \mathrm{L}$ concentration of catalyst, $5.56 \mathrm{mg} / \mathrm{L}$ concentration of $\mathrm{MO}, 80$ minutes illumination time. The amount of catalyst was small, illuminetion time was short and the efficency was high. The research indicates that this kind of catalyst is very potential for photo-oxidation organic dye wastewater in industry.

\section{References}

[1] M. Q. Hu and Y. M. Xu, "Photocatalytic degradation of textile dye X3B by heteropolyoxometalate acids," Chemosphere, Vol. 54, No. 3, 2004, pp. 431-434.

[2] A. Fujishima and K. Honda, "Electrochemical photolysis of water at a semiconductor electrode," Nature, Vol. 238, No. 5358, 1972, pp. 37-38.

[3] A. Troupis, T. M. Triantis, E. Gkika, A. Hiski and E, Papaconstantinou, "Photocatalytic reductive-oxidative degradation of Acid Orange7 by polyoxometalates," Applied Catalysis B: Environmental, Athens, Vol. 86, No.1-2, 2009, pp. 98-107.

[4] P. Kormali, A. Troupis, T. Triantis, A. Hiskia and E. Papaconstantinou, "Photocatalysis by polyoxometallates and $\mathrm{TiO}_{2}$ : A comparative study," Catalysis Today, Vol. 124, No. 3-4, 2007, pp. 149-155.

[5] Y. Yang, Q. Y. Wu, Y. H. Guo, C. W. Hu and E. B. Wang, "Efficient degradation of dye pollutants on nanoporous polyoxotungstate-anatase composite under visible-light irradiation," Journal of Molecular Catalysis A: Chemical, Vol. 225, No. 2, 2005, pp. 203-212.

[6] Y. Q. Wang, L. J. Wang and P. Y. Peng, "Photocatalytic degradation of $\mathrm{L}$-acid by $\mathrm{TiO}_{2}$ supported on the activated carbon," Journal of Environmental Sciences, Vol. 18, No. 3, 2006, pp. 562-566.

[7] I. M. Arabatzis, S. Antonaraki, T. Stergiopoulos, A. Hiskia, E. Papaconstantinou, M. C. Bernard and P. Falaras, "Preparation, characterization and photocatalytic 
activity of nanocrystalline thin film $\mathrm{TiO}_{2}$ catalyststowards 3, 5-dichlorophenol degradation," Journal of Photochemistry and Photobiology A: Chemistry, Vol. 149, No. 1-3, 2002, pp. 237-245.

[8] X. H. Zhu, W. Wang and H. C. Li, "Photocatalysis of phospho-tungstic acid for dye solution degradation," Shanghai Environmental Sciences, Vol. 20, No. 9, 2001, pp. 444-450.

[9] X. H. Zhu, H. C. Li and W. Wang, "Photocatalytic degradation of methyl orange solution with silicotungstic acid," Journal of Dalian Railway Institute, Vol. 22, No. 1, 2001, pp. 101-104.

[10] E. Gkika, A. Troupis, A. Hiskia and E. Papaconstantinou, "Photocatalytic reduction of chromium and oxidation Of organics by polyoxometalates," Applied Catalysis B: Environmental, Vol. 62, No 1-2, 2006, pp. 28-34.

[11] M. Yoon, J. A. Chang, Y. Kim, and J. R. Choi, "Heteropoly acid-incorported $\mathrm{TiO}_{2}$ collids as novel photocatalytic systems resembling the photo-synthetic reaction center," Journal of Physical Chemistry B, Vol. 105, No. 13, 2001, pp. 2539-2545.

[12] S. J. Yang. and H. Y. Tang, "Catalytic synthesis of butanone 1,2-propanediol ketal from phosphotungstic acid/silica," China Chemicals, No. 5, 2008, pp. 36-38.

[13] L. W. Lan, J. Li and Q. Y. Chen, "Photocatalytic Properties for Photocatalytic Water Splitting of $\mathrm{H}_{4} \mathrm{SiW}_{12} \mathrm{O}_{40} /$
$\mathrm{TiO}_{2}$," Nonferrous Metals, No. 3, 2009, pp. 35-38.

[14] C. Trolliet, G. Coudurier and J. C. Vedrine, "Influence of the nature and porosity of different supports on the acidic and catalytic properties of $\mathrm{H}_{3} \mathrm{PW}_{12} \mathrm{O}_{40}$," Topics in Catalysis, Vol. 15, No. 1, 2001, pp. 73-81.

[15] A. Mylonas, A. Hiskia and E. Papaconstantinou, "Contribution to water purification using polyoxometalates aromatic derivatives, chloroacetic acids". Journal of Molecular Catalysis A: Chemical, Vol. 114, No.1-3, 1996, pp. 191-200.

[16] Y. H. Guo and C. W. Hu, "Porous hybrid photocatalysts based on polyoxometalates," Journal of Cluster Science, Vol. 14, No. 4, 2003, pp. 505-526.

[17] A. Mylonas, E. Papaconstantinou and V. Roussis, "Photocatalytic degradation of phenol and p-cresol by polyoxotungstates mechanistic implications," Polyhedron, Vol. 15, No. 19, 1996, pp. 3211-3217.

[18] Y. B. Chen, X. X. Wang, X. Z. Fu and Y.L. Li, "Photocatalytic degradation process of azo dye congo red in aqueous solution," Chinese Journal of Catalysis, Vol.26, No.1, 2005, pp. 37-42.

[19] Y. Yang, Y. H. Guo, C. W. Hu and E. B Wang, "Lacunary Keggin-type polyoxometalates-based macroporous composite films: preparation and photocatalytic activity," Applied Catalysis A: General, Vol. 252, No. 2, 2003, pp 305-314. 